\begin{tabular}{|c|c|}
\hline Title & Growth and maturation of Pacific saury Cololabis saira under Iaboratory conditions \\
\hline Author(s) & $\begin{array}{l}\text { Nakaya, Mitsuhiro; Morioka, Taizo; Fukunəga, Kyouhei; Murakami, Naoto; Ichikawa, Takashi; Sekiya, Sachio; } \\
\text { Suy ama, Satoshi }\end{array}$ \\
\hline Citation & $\begin{array}{l}\text { Fisheries Science, } 76(1), 45-53 \\
\text { https://doi.org/10.1007/s12562-009-0179-9 }\end{array}$ \\
\hline Issue Date & $2010-01$ \\
\hline Doc URL & http:/hdl.handle.net/2115/74498 \\
\hline Rights & $\begin{array}{l}\text { ○ } 2016 \text { 公益社団法人日本水産学会; The final publication is available at www.springerlink.com; @ } 2016 \text { The } \\
\text { Japanese Society of Fisheries Sciee }\end{array}$ \\
\hline Type & article (author version) \\
\hline File Information & 11_FS76 Nakay a et al.pdf \\
\hline
\end{tabular}

Instructions for use 


\section{Growth and maturation of Pacific saury Cololabis saira under laboratory}

\section{2 conditions}

3 Mitsuhiro Nakaya - Taizo Morioka - Kyouhei Fukunaga - Naoto Murakami - Takashi Ichikawa

$4 \cdot$ Sachio Sekiya $\cdot$ Satoshi Suyama

5

6 M. Nakaya ( ) T. Morioka - K. Fukunaga · N. Murakami · T. Ichikawa

7 Hokkaido National Fisheries Research Institute, Fisheries Research Agency, Akkeshi, Akkeshi, Hokkaido

8 088-1108, Japan

$9 \quad$ S. Sekiya

10 Management Section of National Center for Stock Enhancement, Fisheries Research Agency, Yokohama,

11 Kanagawa 220-6115, Japan

12 S. Suyama

13 Hachinohe Branch, Tohoku National Fisheries Research Institute, Hachinohe, Aomori 031-0841, Japan

14 Present address:

15 M. Nakaya

16 Kakikin Corporation, Akkeshi, Hokkaido 088-1111, Japan

17 e-mail: nakayamitsuhiro@yahoo.co.jp

18 Tel \& Fax: +81-135-52-5277

19 
20 Abstract This study details the growth and maturation processes of Pacific saury Cololabis saira from

21 eggs to first spawning under laboratory conditions. They were reared in $20^{\circ} \mathrm{C}$, and fed almost to

22 satiation every day. There was no significant difference in the knob length $(\mathrm{KnL})$ between males and

23 females and therefore data were combined in the following Gompertz growth formula $K n L_{t}=277.1$ exp

$24 \quad(-\exp (-0.015(t-83.8)))$. The first spawning was observed on 243 days after hatching (DAH). At the

25 beginning of spawning, when the mean $\mathrm{KnL}$ was about $250 \mathrm{~mm}$, only several hundred eggs were spawned

26 at most. The spawning continued, and the number of spawned eggs increased notably after 260 DAH.

27 Correlation and stepwise multiple regression analysis of gonad somatic index (GSI) of Pacific saury

28 versus $\mathrm{KnL}, \mathrm{CF}$, and DAH revealed that only DAH $(R=0.88,0.72$, male and female, respectively) was

29 significantly correlated with GSI of Pacific saury $(P<0.001)$. This result suggests that DAH is one of

30 the most influential factors for maturation in this species.

31

32 Keywords Growth $\cdot$ Maturation $\cdot$ Pacific saury $\cdot$ Spawning 
Currently many fisheries species are showing resource depletion and subsequently a reduction in reproductive success [1]. These processes relate not only to global environmental change but also to overfishing $[2,3]$.

Pacific saury Cololabis saira is an important pelagic commercial fish that is widely distributed in the northwestern Pacific [4]. However, because of its wide distribution area, the amount of total stock has not yet been fully estimated and landings in Japan as well as body size distributions of the catch show dramatic fluctuations from year by year $[5,6]$. Fortunately, resources of the species have not been depleted yet unlike many other fisheries species. Therefore we need to understand the causes of these stock fluctuations in order to protect the resource from excess exploitation. To determine the factors causing fluctuations, first we need to obtain information on the life history, age and growth, and reproduction processes. In previous studies on the life history, the general outline was deduced by Hotta [7] and Kosaka [8]. However after Pannella [9] reported the existence of daily growth rings on the otoliths of fish, it has enabled clarification of the growth processes of various kinds of fish species over the period of less than one year after hatching [10-14]. Also for Pacific saury, the microstructure has been observed for the otolith [15], and Watanabe and Kuji [16] showed that the growth rings are formed daily using a laboratory experiment and thus enabling aging of this species. For estimation of adult age, the first spawning would be expected to occur after the formation of the hyaline zone (there is no space between the rings 
and / or the rings can not be seen clearly), however for only $17-27 \%$ of individuals can the rings be counted during this period [17]. Therefore, true age of the first spawning individuals has not yet been obtained [18]. Sampling for larvae and juveniles of Pacific saury which forms the basis of the stock analysis has continued $[19,20]$. Growth and survival in the early life history are well known particularly for the nearshore area of Japan $[6,21,22]$. However as the spawning continues for quite long and the area is widespread in the North Pacific $[7,8]$, the biology of the early life history has not yet been clarified and also their reproduction because the scarcity of samples from the spawning season as no commercial fishing occurs during this season. In general, the initial body size of Pacific saury showing ovary maturation is over $250 \mathrm{~mm}$ knob length $(\mathrm{KnL})$ and the mode is $270 \mathrm{~mm} \mathrm{KnL}$, however the minimum size of individual that has already been observed in a spawning experiment was $253 \mathrm{~mm} \mathrm{KnL} \mathrm{[18].} \mathrm{Also} \mathrm{about}$ $200 \mathrm{~mm} \mathrm{KnL}$ individuals were considered to have taken part in spawning both in the Japan Sea [23] and Suruga Bay [24]. Furthermore other specimens, even at $200 \mathrm{~mm} \mathrm{KnL}$ individuals were found to have over $1 \mathrm{~g}$ wet weight of ovary that are ripe eggs [24]. Thus, viewpoints regarding the growth and maturation of Pacific saury differ among reports, and the causes of the resource fluctuations remain undetermined. However based on the present sampling scale and methods, clarification of these missing links are unlikely to be resolved. Ito et al. [25] suggested that modeling approaches are important tools to identify information and data gaps. To investigate the mechanisms affecting the variability in Pacific saury growth, abundance, and biomass, a model which is able to reveal the effect of environmental and feeding conditions is required. 
However, experimental information on which to base such a model is still limited [26,27], because Pacific saury are easily damaged in rearing tanks [28-31]. In the present study, first we examined the growth and maturation of Pacific saury under laboratory conditions to obtain some parameters for the model of Ito et al. [25].

\section{Materials and Methods}

Fertilized eggs of the Pacific saury, attached to drifting brown algae, were collected by research vessel

81 'Asama' in Kumano-nada, Mie Prefecture $\left(16-17^{\circ} \mathrm{C}\right.$ sea surface temperature), Pacific Ocean Japan on water temperature, 32-34 ppt salinity) with oxygen and then transported to National Fisheries Research Institute, Fisheries Research Agency, Akkeshi by plane. The eggs were stocked and then incubated in a 20 ton concrete tank at a temperature of about $17{ }^{\circ} \mathrm{C}$ (water exchange rate was $120 \%$ / day). After hatching, the larvae were reared in the same tank at a temperature of about $20^{\circ} \mathrm{C}$, because the temperature is the best for growth and survival for Pacific saury (for larvae and juveniles [32], from larvae to adults [28-31]). At 116 days after hatching (DAH), 250 individuals of Pacific saury were transferred to a 40 ton concrete tank. The fish were fed to almost satiation on live food (rotifers Brachionus spp., and Artemia nauplii): usually two times a day (08:00-09:00, 15:00-16:00), frozen copepods (Miyabi No. 1

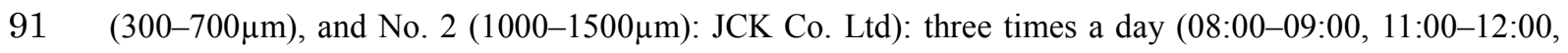


thoroughly mixed): 10-20 times a day (depending on their appetite) using a self feeding machine during

94 06:00-17:00, mince (made of frozen mysid and squid): Monday, Wednesday, and Friday in the morning 10:00-11:00). Daily feed amount and details of the rearing conditions are shown in Table 1. Samples of over 20 individuals were collected every 5 days from 0 to $40 \mathrm{DAH}$, from 50 to $140 \mathrm{DAH}$ samples of 10-20 individuals every 10 days, from 160 to 260 DAH 10 individuals were collected every 20 days, and when we could observe different or unusual behaviors related to spawning. The sampling was done at feeding time because the fish could be readily caught without causing excess stress.

$100 \mathrm{KnL}$ and body weight in wet weight (BW) of Pacific saury were measured to the nearest $0.1 \mathrm{~mm}$ and $0.01 \mathrm{~g}$ after being anaesthetized with FA100 (Dainippon Pharma) or in seawater chilled with ice. $\mathrm{KnL}$ is a unit of body length from the edge of the lower jaw to the edge of the meat of silver part which is inside the caudal fin. This part has been shown to have the least measurement bias for Pacific saury [33]. In addition, the condition factor (CF) was examined using the following formula. $C F=\left(B W / K n L^{3}\right) \times 10^{6}$ that were collected after 190 DAH were measured for the gonad weight $(G W)$ and gonad somatic index $(G S I)$ calculated. $\quad G S I$ was calculated using the following formula.

111 Ovary observations were done using females after 200 DAH that had yet to spawn. Multiple regression 
114 To estimate the distribution of their egg diameter, eggs were sampled from 100 randomly selected 115 individuals in the middle part of gonad and then their size was measured to the nearest $0.01 \mathrm{~mm}$.

116 Measurements of the egg diameter were based on the method of Suyama [17]. Eggs size was calculated

117 using the equation below.

118 Radius $=\left(\left(\text { long radius }{ }^{2}+\text { short } \text { radius }^{2}\right) / 2\right)^{1 / 2}$

119 To estimate batch eggs of the first spawning, largest oocytes were counted at one side of the ovary

120 under the stereomicroscope.

121 From after $200 \mathrm{DAH}, 2$ pieces of spawning beds (we cut $16 \mathrm{~mm}$ diameter polyvinyl chloride pipe to a

122 thickness of $2 \mathrm{~mm}$ width and connected 20 pieces with fine line, like beads (Fig. 1a)) were set in the

123 breeding tank to measure the wet weight of eggs spawned every day (one time a day: 08:00-09:00). The

124 number of eggs laid was estimated after verification of whether any eggs had come off and sank or not

125 (the eggs are heavier than seawater). That is, whether they attached only to the spawning materials or not,

126 and whether cannibalism of eggs occurred (stomach contents of the broodstock were observed by using

127 one part of the sample). The eggs laid on the spawning materials (Fig. 1b) were then removed, wet

128 weight measured, and used as the number of eggs spawned. Eggs of Pacific saury are elliptical (length:

$1291.8 \pm 0.04 \mathrm{~mm}$ (mean \pm SD), width: $1.6 \pm 0.06 \mathrm{~mm}$ ). Wet weight of one egg with attachment filament

130 was calculated as $0.0033 \mathrm{~g}$, and then one gram of the egg mass was estimated to be 300 eggs in this study.

131 Three types of growth model (Logistic, von Bertalanffy, and Gompertz) of Akaike Information

132 Criterion [35] calculated using the non-linear least-squares regression procedure (Microsoft Excel solver 
134 model to data. Difference of growth between sexes was compared with ANCOVA using log transformed data.

\section{Results}

The relationships between $\mathrm{DAH}$ and $\mathrm{KnL}$, and between $\mathrm{DAH}$ and $\mathrm{BW}$ under $20^{\circ} \mathrm{C}$ breeding conditions

142 (details shown in Table 1) are shown in Figs. 2, 3. Mean body size of 0 DAH larvae was $6.9 \pm 0.26 \mathrm{~mm}$

$143 \mathrm{KnL}($ mean $\pm \mathrm{SD}$ ), and $5 \mathrm{DAH}$ larvae was $7.7 \pm 0.59 \mathrm{~mm} \mathrm{KnL}$. Observations of Pacific saury larvae

144 immediately after hatching showed that their digestive tract had not been fully formed yet, although 1

145 DAH larvae already had a functioning digestive tract, therefore, feeding of rotifers started 1 DAH and

146 continued until 5 DAH. Feeding of Artemia nauplii started from 2 DAH, and continued until 40 DAH

$147(41.1 \pm 4.73 \mathrm{~mm} \mathrm{KnL}) . \quad$ Frozen copepods and artificial feed (Otohime A, B1) started to be fed after 15

148 DAH $(13.0 \pm 1.87 \mathrm{~mm} \mathrm{KnL})$. On $35 \mathrm{DAH}(35.9 \pm 3.99 \mathrm{~mm} \mathrm{KnL})$, an auto feeding machine started to be

149 used. At this time, the main artificial feed was Otohime B1, B2. From after 140 DAH (186.9

$150 \pm 13.66 \mathrm{~mm} \mathrm{KnL}$ ), we fed not only artificial feed (Hirame EP1), but also fed raw mince. 
154 After 140 DAH individuals that could be judged whether they were female or male by observation of the

155 gonad under a stereomicroscope were used for estimation of the growth process separately for both male

156 and female (Fig. 4). Their regressions lines are shown below:

$157 \quad$ Male: $y=0.54 x+114.0 \quad\left(n=60, R^{2}=0.70\right)$

$158 \quad$ Female : $y=0.56 x+109.9\left(n=63, R^{2}=0.72\right)$

159 where $x$ means DAH, and $y$ means KnL. The regressions of the above two formulas were significant $(P$

$160<0.001)$ and there was no significant difference for both slope and intercept $(P=0.98, P=0.77$,

161 respectively) and therefore, the growth formulas were combined for both sexes.

162 Three types of growth regressions calculated (Logistic, Gompertz, von Bertalanffy), and then their equations were judged by Akaike Information Criterion. As a result, the Gompertz growth formula was adopted (Fig. 2). The formula is as follows:

After 190 DAH, we observed and measured their gonads (Figs. 5, 6 and 7). According to Suyama et al.

171 [18] from the cortical alveoli stage to the primary yolk stage, GSI of Pacific saury notably increases and 

234.7mm KnL $(\mathrm{GSI}=2.80$, gonad weight $=1.7 \mathrm{~g}, 310 \mathrm{DAH}) . \quad$ After $300 \mathrm{DAH}$, all female individuals were over 1 GSI, except for 1 individual (GSI 0.91-4.20, gonad weight $0.9-5.5 \mathrm{~g}$ ). The male fish exceeding 1.0 GSI also already had produced a sufficient quality of sperm in their testes to join the spawning (Suyama Unpublished). The first individuals observed that had over 1 GSI was a male on 190 DAH $(\mathrm{GSI}=1.14$, gonad weight $=0.6 \mathrm{~g}) . \quad$ And also the male was a minimum size that had over $1 \mathrm{GSI}$ (223.6 mm KnL). After 300 DAH, all male individuals were over 1 GSI (GSI 2.18-3.43, gonad weight $2.5-5.5 \mathrm{~g})$. Correlation and stepwise multiple regression analysis of GSI of Pacific saury versus $\mathrm{KnL}, \mathrm{CF}$, and DAH revealed that only DAH ( $R=0.88,0.72$, male and female, respectively) was significantly correlated with GSI of Pacific saury $(P<0.001)$.

(Fig. 8). Although $99 \%$ of oocyte diameter range showed overlap (oocyte in the early yolk vesicle stage, number was estimated to be $289-350$. 
194 the same cycle (every 3-4 days). At 94 days after first spawning, the total of spawned eggs from first spawning was over 200,000 (number of breeding individuals at first spawning day: 89 individuals, 94

196 days after first spawning: 47 individuals). These spawned eggs that attached to the spawning materials were almost $100 \%$ fertilized.

\section{Discussion}

So far many studies have examined the growth and maturation of wild Pacific saury, however there has

fish. The body size estimates for 6 month old fish by Matsumiya and Tanaka [36] are $182 \mathrm{~mm} \mathrm{KnL,}$

Watanabe et al. [37] and Suyama [17] are about 200mm KnL respectively.

207 In this study, the water temperature was maintained at $20^{\circ} \mathrm{C}$ and the fish were fed to satiation as a condition. Their growth until a half year after hatching (180DAH: $207.5 \pm 19.6 \mathrm{~mm} \mathrm{KnL} \mathrm{(mean}$

$209 \pm \mathrm{SD})$ ) was similar to that in the wild, though the environmental conditions and prey items were quite different and also includes a variety of stress. According to Odate [38], wild individuals of Pacific saury

211 migrate from warm sea areas to the Oyashio area (cold sea: sea surface temperature is about $12^{\circ} \mathrm{C}$ ) on 
$213 \mathrm{~m}^{2}$ ), though the temperature is low [38]. This migration enhances the growth rate and maturation of this

214 species, although the metabolic mechanisms have not yet been fully clarified. This study was carried

215 out under the optimum temperature condition for growth of Pacific saury (for larvae and juveniles [32],

216 from larvae to adults [28-31]: that is $20^{\circ} \mathrm{C}$ ) with enough food at this temperature. Therefore, the

217 growth process of this study would show similar to the growth process in the wild.

218 From half a year after hatching, opinions on their growth vary among studies. Matsumiya and

219 Tanaka [36] estimate that this species grows up $223 \mathrm{~mm} \mathrm{KnL}$ at one year based on size distribution. The

220 Pacific saury caught from the western North Pacific were divided into three groups; the small size

$221 \quad(200-240 \mathrm{~mm} \mathrm{KnL})$, medium size (241-280mm KnL) and large size (> 280mm KnL) [39]. Watanabe et

222 al. [37] estimate the period to grow from a small size (200-240mm KnL) to a large size (>280mm KnL)

223 to be half a year, and Suyama [17] estimates for the same period to be one year based on daily growth

224 ring analysis. The reason for the difference of opinions is the existence of hyaline zones on the otolith.

225 The zone does not have clear daily growth rings making the count of the number difficult. This study

226 used reared individuals that were reared from eggs, therefore there is no doubt regarding the relationships

227 between age and growth. Thus, we directly and firstly obtained evidence for the growth from half a year

228 after hatching. The mean body size of $336 \mathrm{DAH}$ individuals was $270 \mathrm{~mm} \mathrm{KnL}$. This size is included in

229 middle sized fish category $(241-280 \mathrm{~mm} \mathrm{KnL})$ used for grading commercially landed fish. And the

230 growth process (Fig. 2) expected that the growth speed would be quite slow after growth to the middle

231 size $(241-280 \mathrm{~mm} \mathrm{KnL})$ and it would spend much time to grow to the large size $(>280 \mathrm{~mm} \mathrm{KnL})$. 
During the start of the spawning period, one spawner might spawn eggs a few at a time, or one or two

spawners might spawn in turn. As their gonad weight was about $1 \mathrm{~g}$ at most when the spawning began

237 (GSI was about 1), the number of eggs released would total about 300 eggs. The number of peaks of

238 the attached eggs on the spawning materials increased sharply after 60 days after first spawning (300

239 DAH, estimated mean body size: $266.5 \mathrm{~mm} \mathrm{KnL}$ ). At the time, the reason may be that not only most of

240 the individuals started to spawn, but also the number of eggs per batch increased for each spawner.

241 After $300 \mathrm{DAH}$, most of the females spawned.

242 So far there are some reports about the number of eggs per batch for Pacific saury (Kubo [40]:

eggs (mean: 2000)). In this study, we measured their oocyte diameter using 200 to $220 \mathrm{DAH}$ individuals

that had no experience of spawning. Although $99 \%$ of oocyte diameters showed overlap, the remaining

estimated as 289-350 oocytes. The number of batch eggs at the first spawning was estimated to be due to the samples including a variety of spawners that have different spawning experience like first, 

spawn, though the body size is small. We need to continue rearing this batch to estimate the total number of spawned eggs in a lifetime. Total number of the spawned eggs in a single spawning season or spawning interval may change due to the feeding conditions during the spawning period. For example for northern anchovy [42] and Japanese anchovy [43], it is pointed out that the feeding conditions during the spawning period would effect the amount of eggs produced $[44,45]$. Feeding condition during spawning season also effect the growth. Further investigation is needed to compare the rearing data and the field data in order to obtain more biological data on this species under a variety of environmental conditions.

Acknowledgements We are grateful for the help of Mr. Hirokatsu Yamada (Mie Prefecture) for collection of the eggs, support and invaluable suggestions and Messrs Jun Tsuzaki and Shinya Yamauchi (Aquamarine Fukushima, Fukushima), Dr. Masayasu Nakagami, Mr. Tadao Jinbo (Minamiizu station, 
4. Hubbs CL, Wisner RL (1980) Revision of the sauries (Pisces, Scomberesocidae) with description of two new genera and one new species. Fish Bull US 77: 521-566

5. Fukushima S, Watanabe Y, Ogawa Y (1990) Correspondence of spawned season to large, medium, and small size Pacific saury exploited in the northwestern Pacific Ocean. Bull Tohoku Natl Fish Res Inst $\quad 52: 17-27 \quad$ (in Japanese with English abstract)

6. Watanabe Y, Oozeki Y, Kitagawa D (1997) Larval parameters determining preschooling juvenile

7. Hotta H (1964) Biological studies and fisheries of the saury, Cololabis saira (Brevoort).

8. Kosaka J (2000) Life history of the Pacific saury Cololabis saira in the northwest Pacific and 
9. Panella G (1971) Fish otoliths: daily growth layers and periodical patterns. Science 173:

10. Nishimura A, Yamada J (1984) Age and growth of larval and juvenile walleye pollock, Theragra chalcogramma (Pallas), as determined by otolith daily growth increments. J Exp Biol Ecol 82:

11. Tabeta O, Tanaka K, Yamada J, Tzeng W (1987) Aspect of the early life history of the Japanese eel Anguilla japonica determined from otolith microstructure. Nippon Suisan Gakkaishi 53: 1727-1734

12. Nishimura A, Yamada J (1988) Geographical differences in early growth of walleye pollock Theragra chalcogramma, estimated back-calculation of otolith daily growth increments. Mar Biol 97: $220-225$

13. Campana SE (1996) Year-class strength and growth rate in young Atlantic cod Gadus morhua.

14. Plaza G, Katayama S, Omori M (2001) Otolith microstructure of the black rockfish, Sebastes

15. Nishimura A, Watanabe Y, Yamada H (1985) Daily growth increment-like microstructure in otoliths of the Pacific saury Cololabis saira. Bull Tohoku Reg Fish Res Lab 47: 233-241 (in Japanese with English abstract)

16. Watanabe Y, Kuji Y (1991) Verification of daily growth increment formation in saury otoliths by rearing larvae from hatching. Japan J Ichthyol $38: 1-15$ 

saury Cololabis saira in the central North Pacific Ocean determined by otolith daily growth increments. Nippon Suisan Gakkaishi 58: 1607-1614 (in Japanese with English abstract)

18. Suyama S, Sakurai Y, Shimazaki K (1996) Maturation and age in days of Pacific saury Cololabis

20. Watanabe Y (1991) Possible density-dependent dynamics of larval and juvenile saury population in the northwestern Pacific ocean. Rept Fish Res Invest Japan Gov 27: 79-89 (in Japanese)

21. Watanabe Y, Lo NGH (1988) Larval production and mortality of Pacific saury, Cololabis saira, in the north-western Pacific Ocean. Fish Bull US 78: 601-613

22. Watanabe Y, Kurita Y, Noto M, Oozeki Y, Kitagawa D (2003) Growth and survival of Pacific saury Cololabis saira in Kuroshio-Oyashio transitional waters. J Oceanogra 59: 403-414

23. Sugama K (1957) Analysis of population of the saury (Cololabis saira Brevoort) on the basis of character of otolith-I. Bull Hokkaido Reg Fish. Res Lab 16: 1-12

24. Hotta H (1960) On the analysis of the population of the saury (Cololabis saira) based on the scales and the otolith characters, and their growth. Bull Tohoku Reg Fish Res Lab 16: 41-64 (inJapanese with English abstract)

a fish bioenergetics model of Pacific saury coupled to a lower trophic ecosystem model. Fish 
26. Hotta H (1958) On the growth of the young saury, (Cololabis saira) in the rearing experiment.

27. Kawamura T (1990) Rearing young saury, Cololabis saira (Brevoort). J Jpn Assoc Zoo Aqu (2): $2-3 \quad$ (in Japanese) (3): 1-2 (in Japanese) (1): 1-2 (in Japanese) (2): 1-2 (in Japanese)

32. Oozeki Y, Watanabe Y (2000) Comparison of somatic growth and otolith increment growth in laboratory-reared larvae of Pacific saury, Cololabis saira, under different temperature condition. Mar Biol 136: 349-359

33. Kimura K (1956) The standard length of the Pacific saury, Cololabis saira (Brevoort). Bull 
36. Matsumiya Y, Tanaka S (1974) Considerations on the so-called large-and intermediate-sized fish

37. Watanabe Y, Butler JL, Mori T (1988) Growth of Pacific saury, Cololabis saira, in the northeastern and northwestern Pacific Ocean. Fish Bull US 86: 489-498

38. Odate K (1994) Zooplankton biomass and its long-term variation in the western North Pacific English abstract)

39. Suyama S (2002) Study on the age, growth, and maturation process of Pacific saury Cololabis saira (Brevoort) in the North Pacific. Bull Fish Res Agen 5: 68-113 (in Japanese with English

40. Kubo Y (1954) A ecology study of Cololabis saira (Brevoort) in the Pacific Ocean-II. Studies on the genital gland. Bull Fish Exp Sta Ibaraki 87-97 (in Japanese)

41. Hatanaka M (1956) Biological studies on the population of the saury, Cololabis saira (Brevoot).

42. Hunter JR, Macewicz BJ (1985) Rates of atresia in the ovary of captive and wild northern anchovy, 
374 44. Kurita Y (2003) Energetics of reproduction and spawning migration for Pacific saury (Cololabis saira). Fish Physiol Biochem 28: 271-272

376 45. Kurita Y (2006) Procedures to estimate reproductive traits of fish by combining field surveys and 377 tank experiments. Bull Fish Res Agen Suppl. 4: 87-99 (in Japanese with English abstract) 
Table 1 Details of the daily feeding amount and breeding conditions of Pacific saury Cololabis saira in this experiment

\begin{tabular}{|c|c|c|c|c|c|c|c|c|c|c|c|}
\hline $\begin{array}{l}\text { Days after } \\
\text { hatching }\end{array}$ & $\begin{array}{l}\text { Mean } \\
{ }^{\mathrm{a} K n L} \\
(\mathrm{~mm})\end{array}$ & $\begin{array}{c}\text { Mean } \\
\text { Body } \\
\text { weight } \\
\text { (wet: g) }\end{array}$ & $\begin{array}{l}{ }^{\text {bRotifers }} \\
\text { (inds/ml) }\end{array}$ & $\begin{array}{l}{ }^{\mathrm{b}} \text { Artemia } \text { nauplii } \\
\quad \text { (inds } / \mathrm{ml} \text { ) }\end{array}$ & $\begin{array}{l}\text { 'Frozen } \\
\text { copepods } \\
(\%)\end{array}$ & $\begin{array}{l}{ }^{\mathrm{c} A r t i f i c i a l} \\
\text { feed (\%) }\end{array}$ & ${ }^{\mathrm{c} M i n c e}(\%)$ & $\begin{array}{c}\text { Breeding } \\
\text { individuals }\end{array}$ & $\begin{array}{c}\text { Water } \\
\text { temperature } \\
\left({ }^{\circ} \mathrm{C}\right)\end{array}$ & $\begin{array}{l}\text { Water volume of } \\
\text { the tank }(t)\end{array}$ & $\begin{array}{l}\text { Daily water } \\
\text { exchange rate } \\
\text { (\%) }\end{array}$ \\
\hline 5 & 77 & & 40 & 10 & & & & 8320 & 200 & 12 & 300 \\
\hline 10 & 102 & & & 15 & & & & 6718 & 200 & 12 & 300 \\
\hline 20 & 181 & 002 & & 20 & 1230 & 310 & & 4864 & 200 & 12 & 300 \\
\hline 30 & 283 & 009 & & 30 & 330 & 83 & & 4000 & 200 & 12 & 300 \\
\hline 40 & 411 & 027 & & 40 & & 100 & & 3858 & 200 & 12 & 300 \\
\hline 50 & 536 & 057 & & & & 100 & & 2510 & 200 & 12 & 480 \\
\hline 60 & 672 & 112 & & & & 100 & & 2422 & 200 & 12 & 480 \\
\hline 80 & 998 & 382 & & & & 80 & & 2380 & 200 & 12 & 480 \\
\hline 100 & 1257 & 712 & & & & 80 & & 1225 & 200 & 12 & 480 \\
\hline 120 & 1594 & 1560 & & & & 80 & & 250 & 200 & 12 & 300 \\
\hline 140 & 1869 & 2888 & & & & 70 & 45 & 229 & 200 & 20 & 300 \\
\hline 160 & 1972 & 3342 & & & & $37-40$ & $30-39$ & 200 & 200 & 20 & 0 \\
\hline 180 & 2075 & 3813 & & & & $37-40$ & 53 & 149 & 200 & 20 & 0 \\
\hline 200 & 2267 & 5346 & & & & $37-40$ & 42 & 132 & 196 & 20 & 0 \\
\hline 250 & 2484 & 7678 & & & & $37-40$ & 57 & 76 & 200 & 20 & 0 \\
\hline 327 & 2885 & 13567 & & & & 33 & 41 & 27 & 201 & 20 & 0 \\
\hline 340 & 2870 & 12174 & & & & 27 & 42 & 23 & 199 & 20 & 0 \\
\hline
\end{tabular}

a KnL means knob length
bFeeding density at each feeding

cDaily feeding amount per body wet weight of Pacific saury 
378 Fig. 1 Spawning beds (using $16 \mathrm{~mm}$ diameter polyvinyl chloride pipe (a)), the eggs (b) and spawning 379 behavior of Pacific saury Cololabis saira (c)

380 Fig. 2 Relationships between days after hatching (DAH) and knob length (KnL) of Pacific saury

\section{$381 \quad$ Cololabis saira}

382 Fig. 3 Relationships between days after hatching (DAH) and body weight in wet weight (BW) of 383 Pacific saury Cololabis saira

384 Fig. 4 Relationships between days after hatching (DAH) and knob length (KnL) of Pacific saury 385 Cololabis saira for each sex

386 Fig. 5 Relationships between knob length (KnL) and gonad somatic index (GSI) of Pacific saury 387 Cololabis saira

388 Fig. 6 Relationships between knob length (KnL) and gonad somatic index (GSI) of Pacific saury

389 Cololabis saira

390 Fig. 7 Relationships between days after hatching (DAH) and gonad somatic index (GSI) of Pacific

Fig. 8 Distribution of egg diameter of Pacific saury Cololabis saira before first spawning

393 Fig. 9 Relationships between days after first spawning and number of eggs released each day by the 

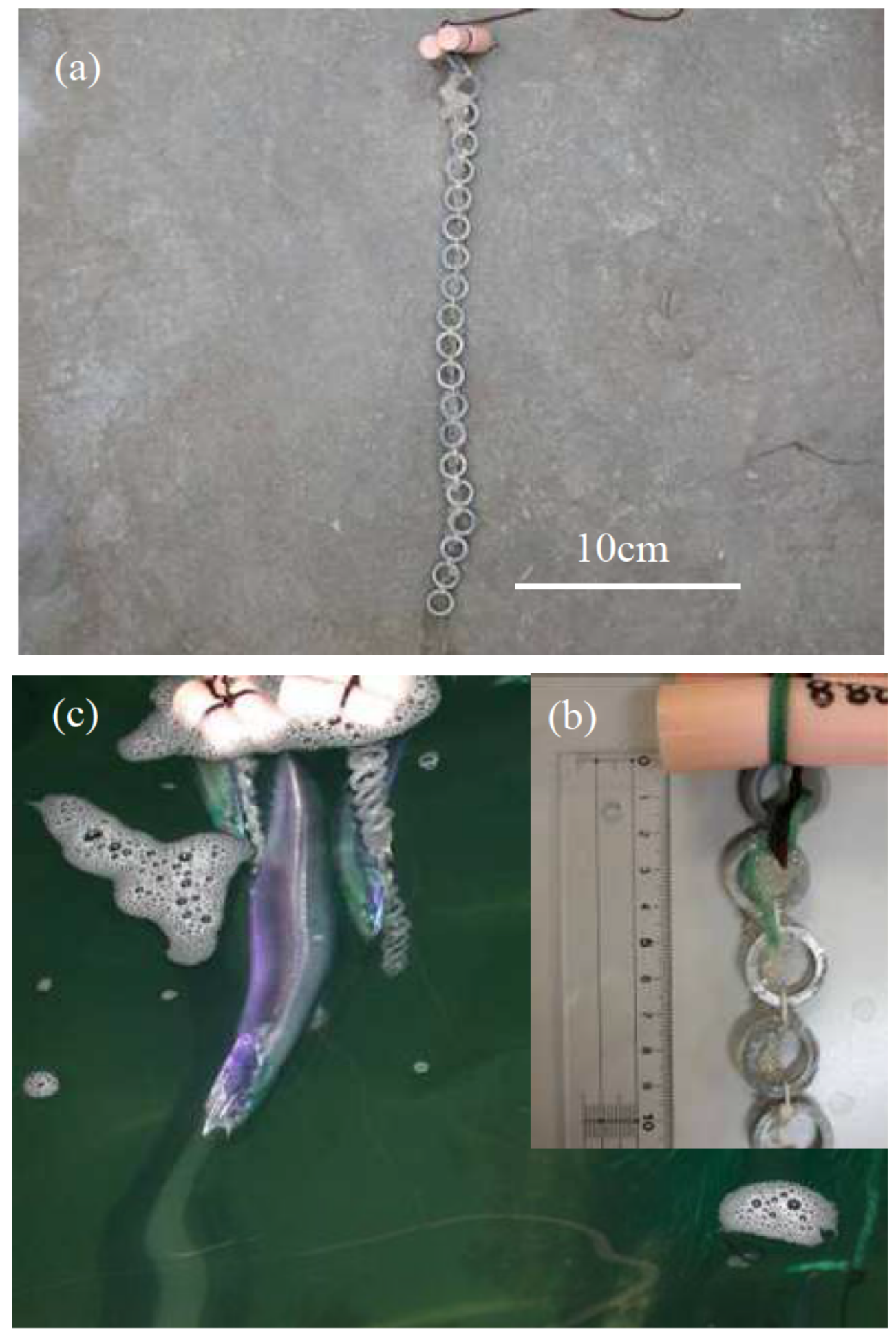

Fig. 1 Nakaya et al. 


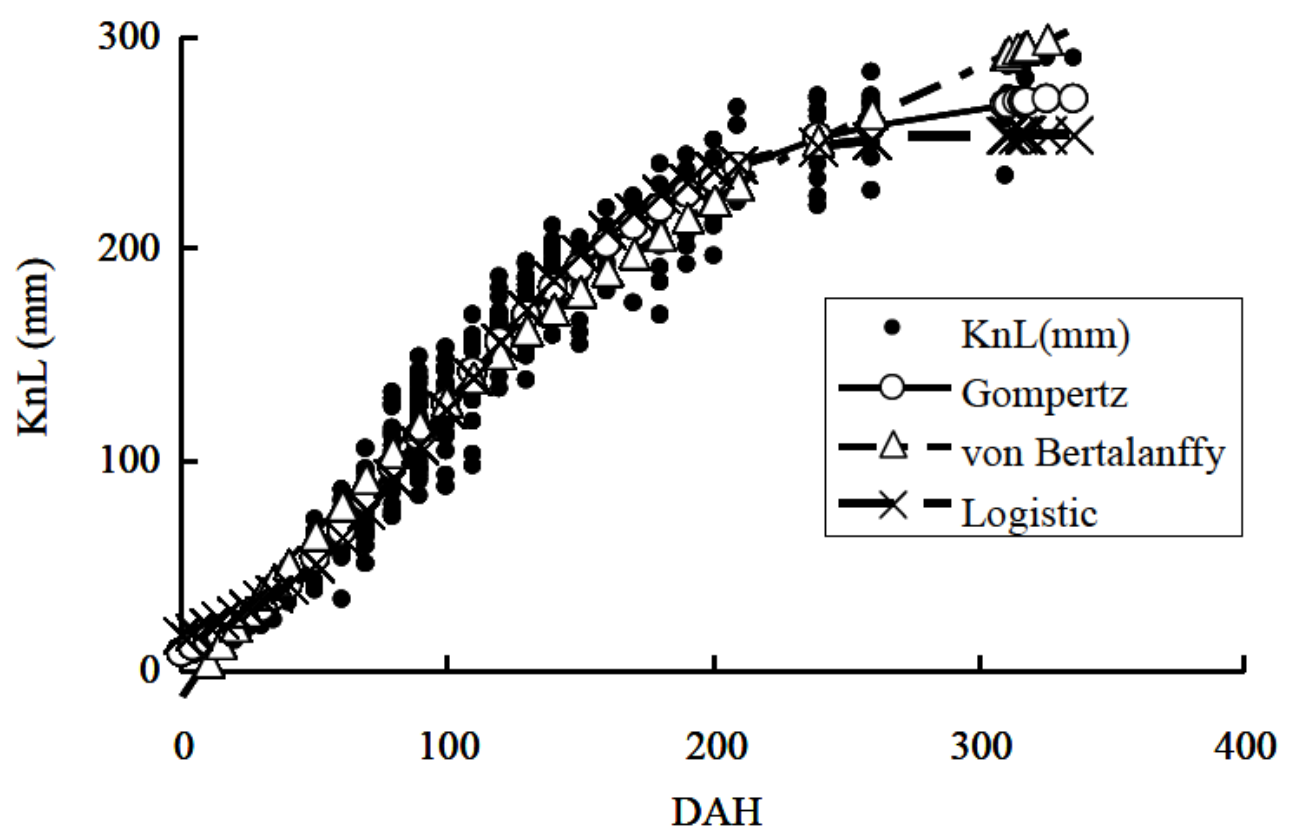

Fig. 2 Nakaya et al. 


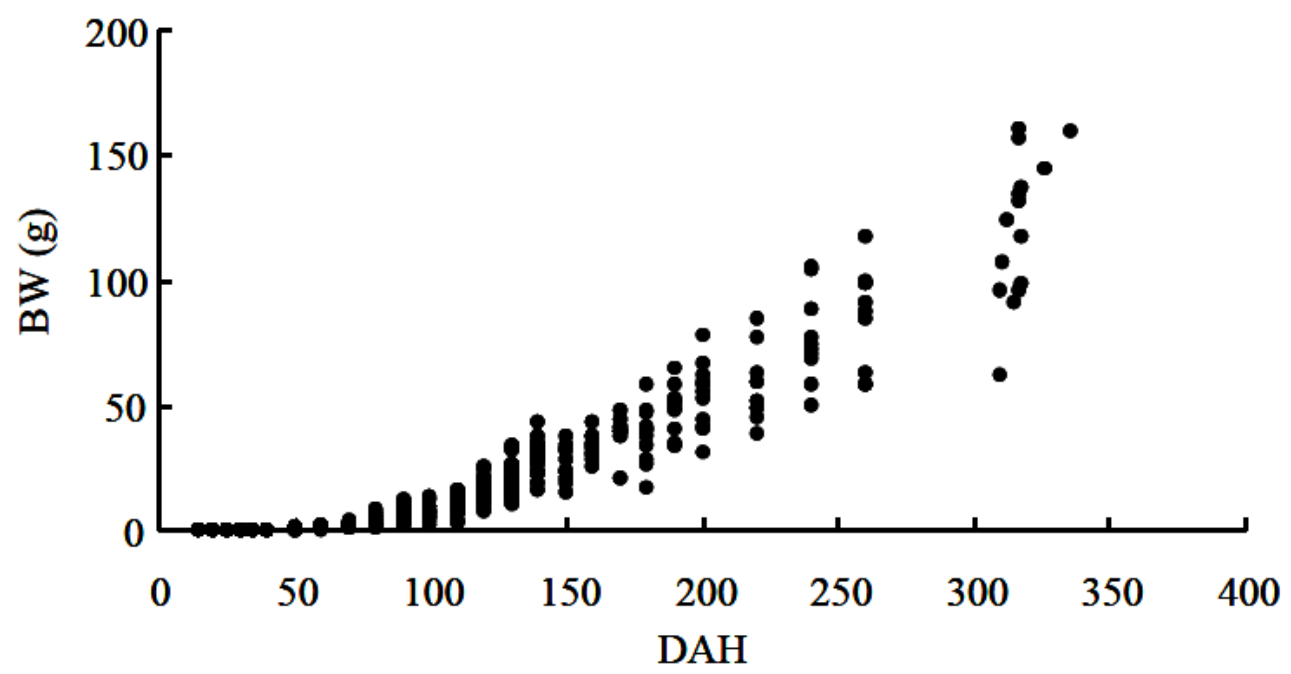

Fig. 3 Nakaya et al. 


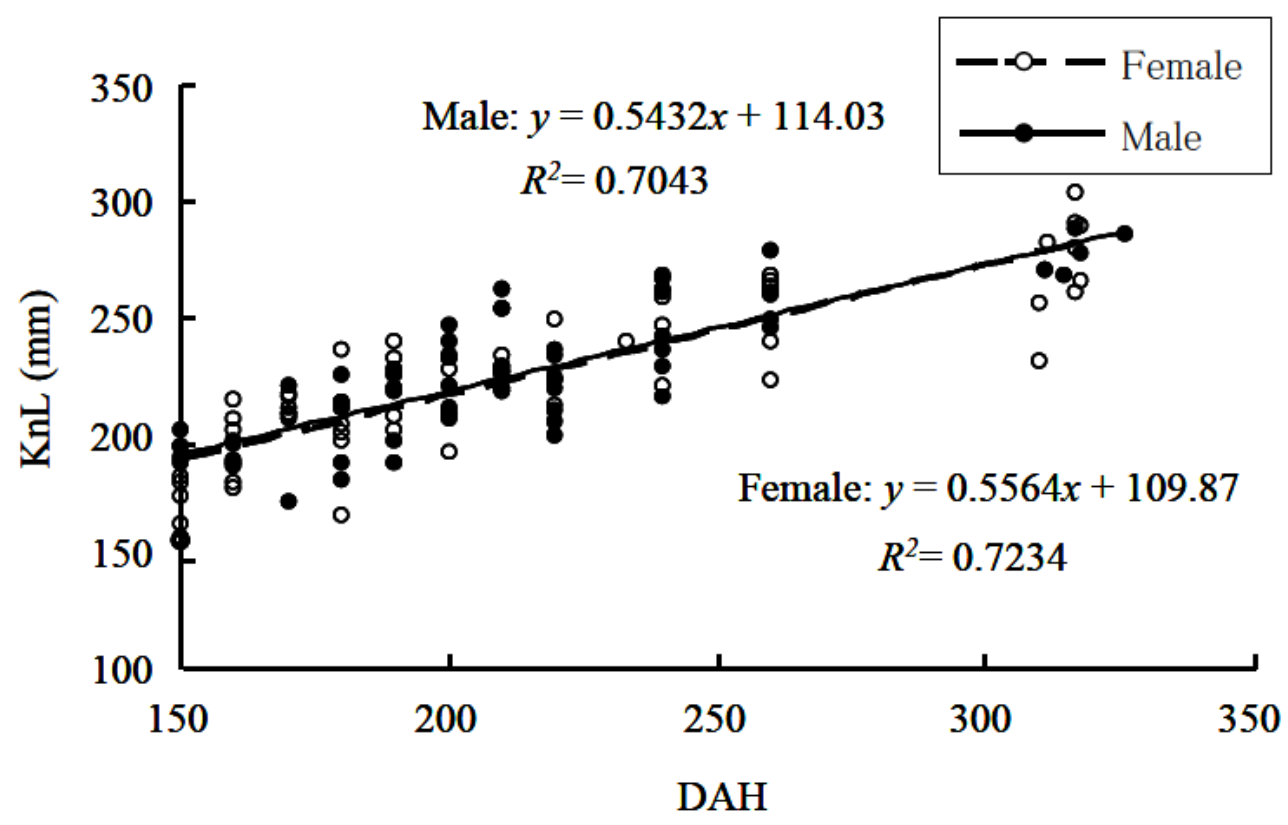

Fig. 4 Nakaya et al. 


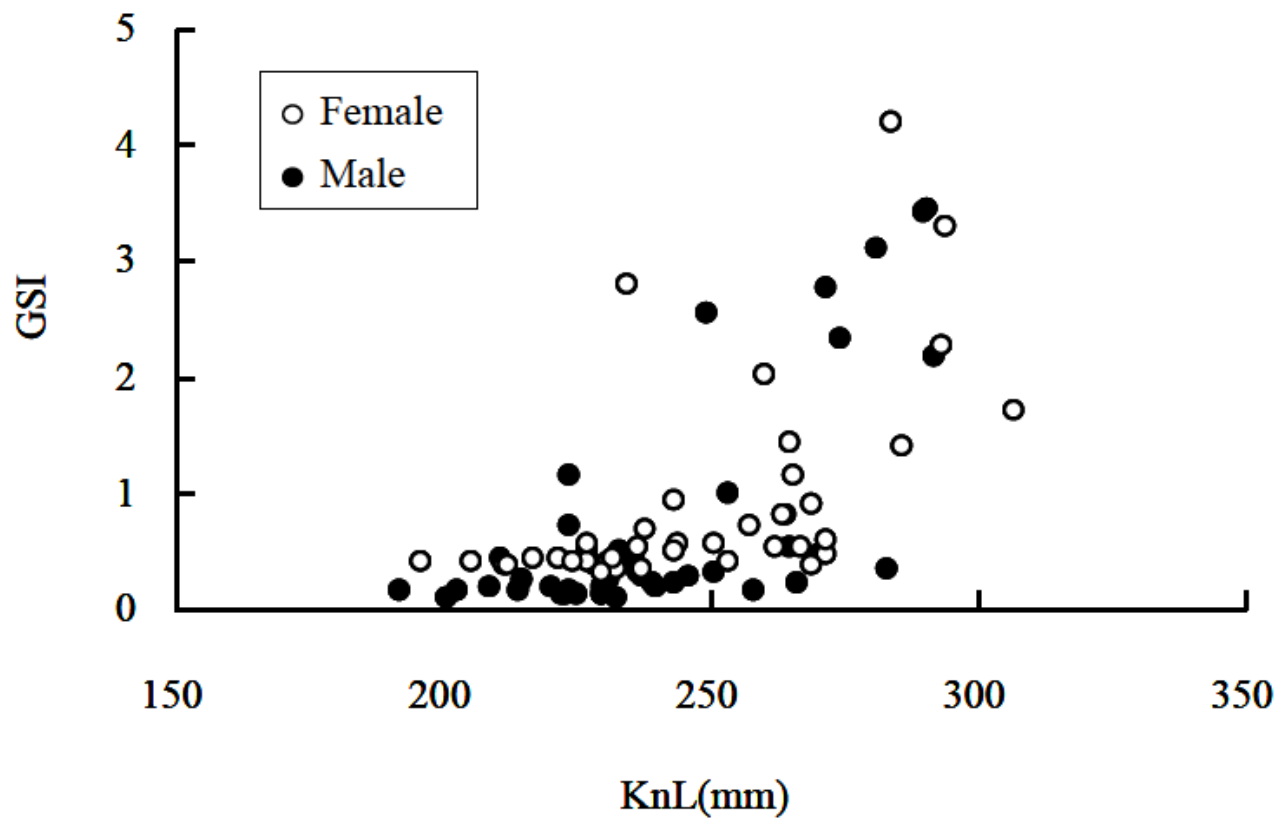

Fig. 5 Nakaya et al. 


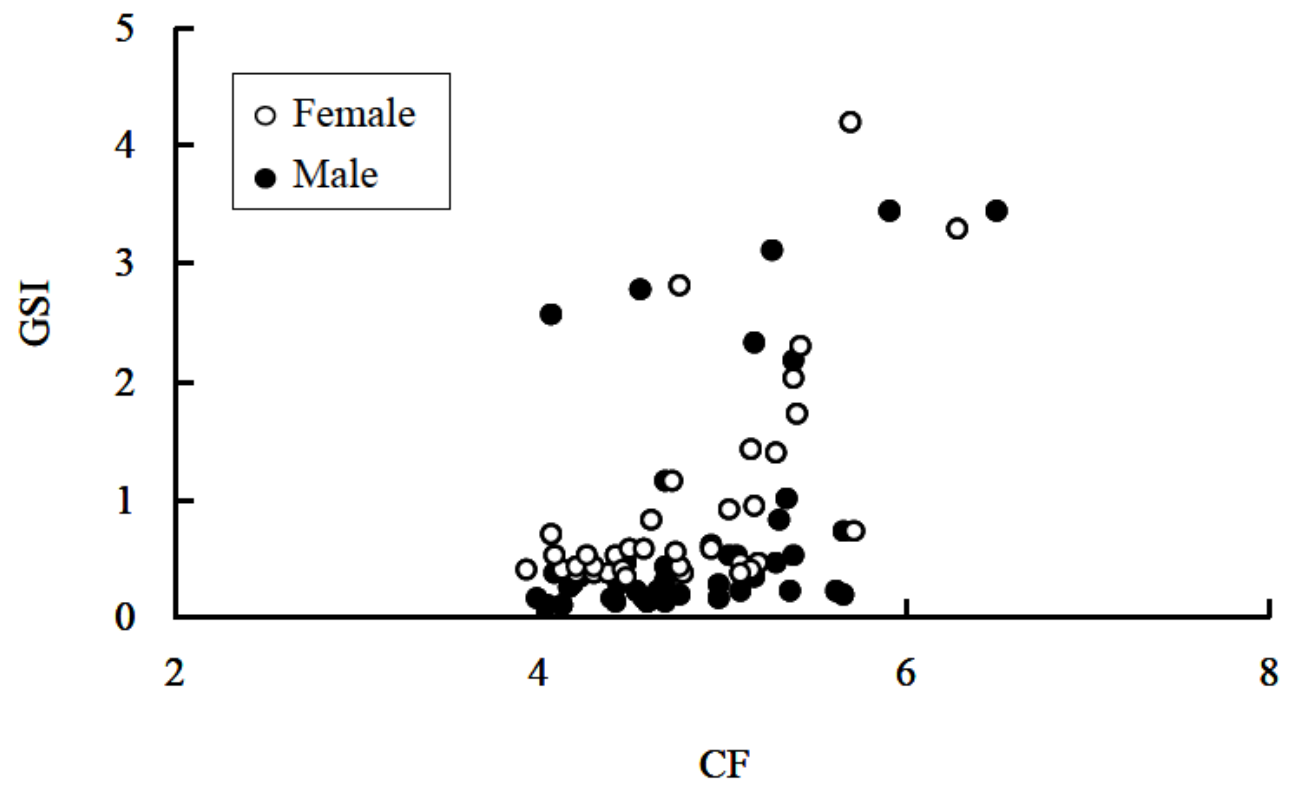

Fig. 6 Nakaya et al. 


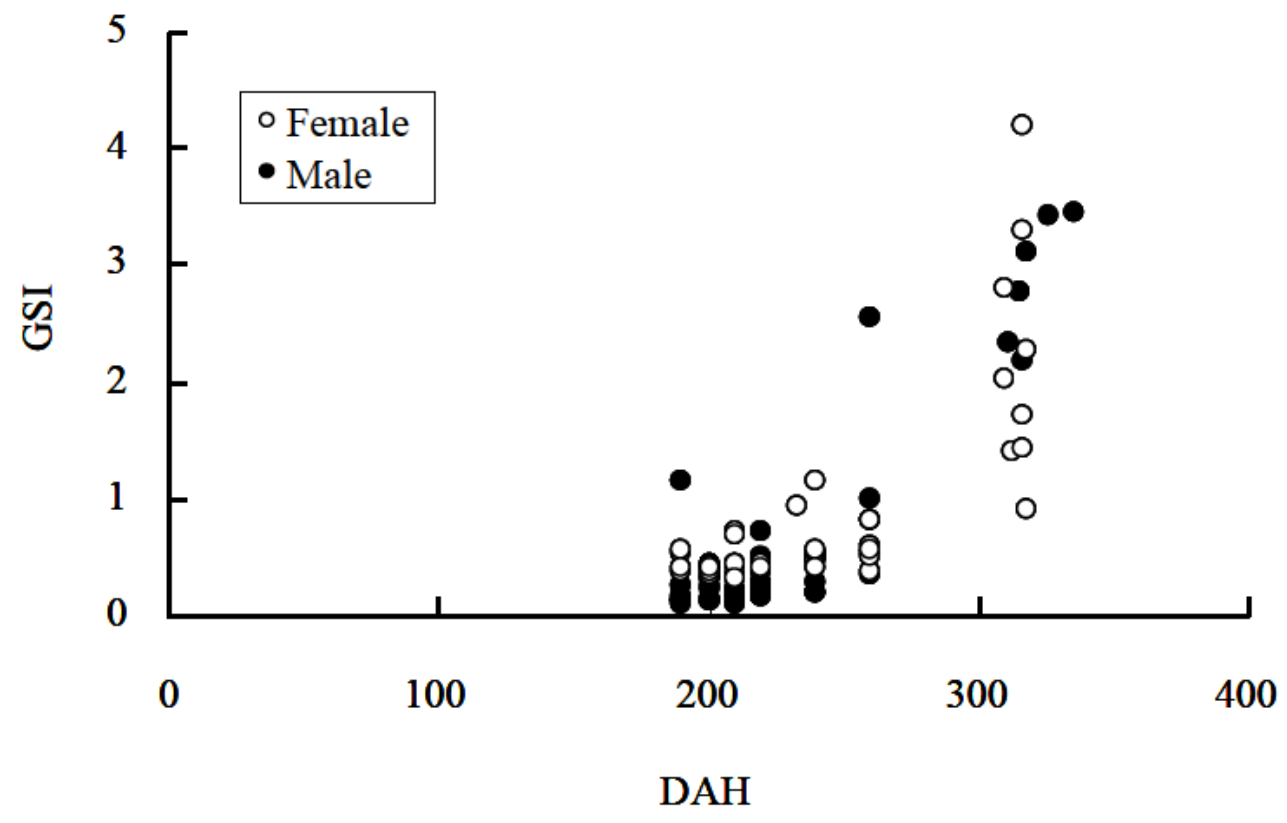

Fig. 7 Nakaya et al. 


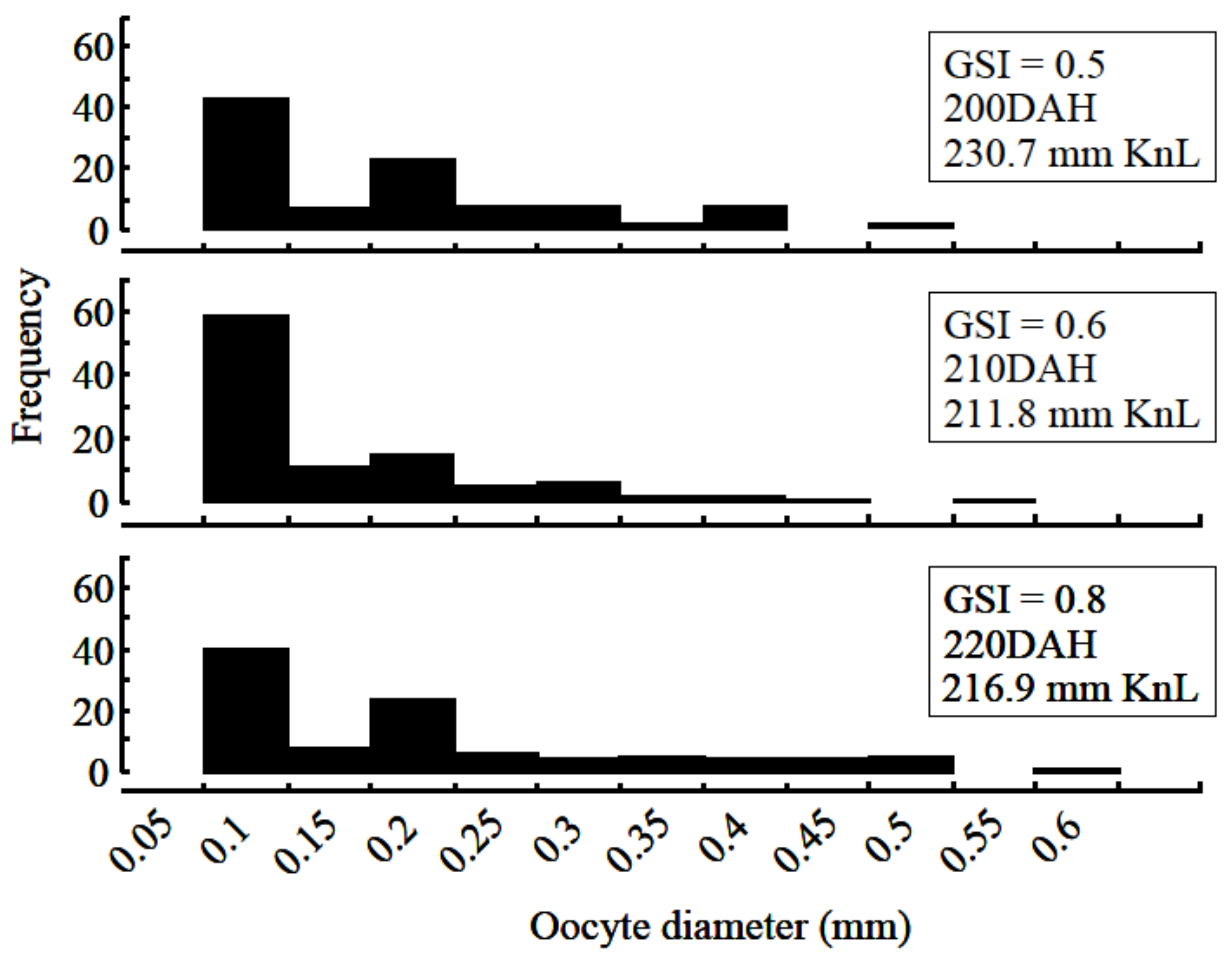

Fig. 8 Nakaya et al. 


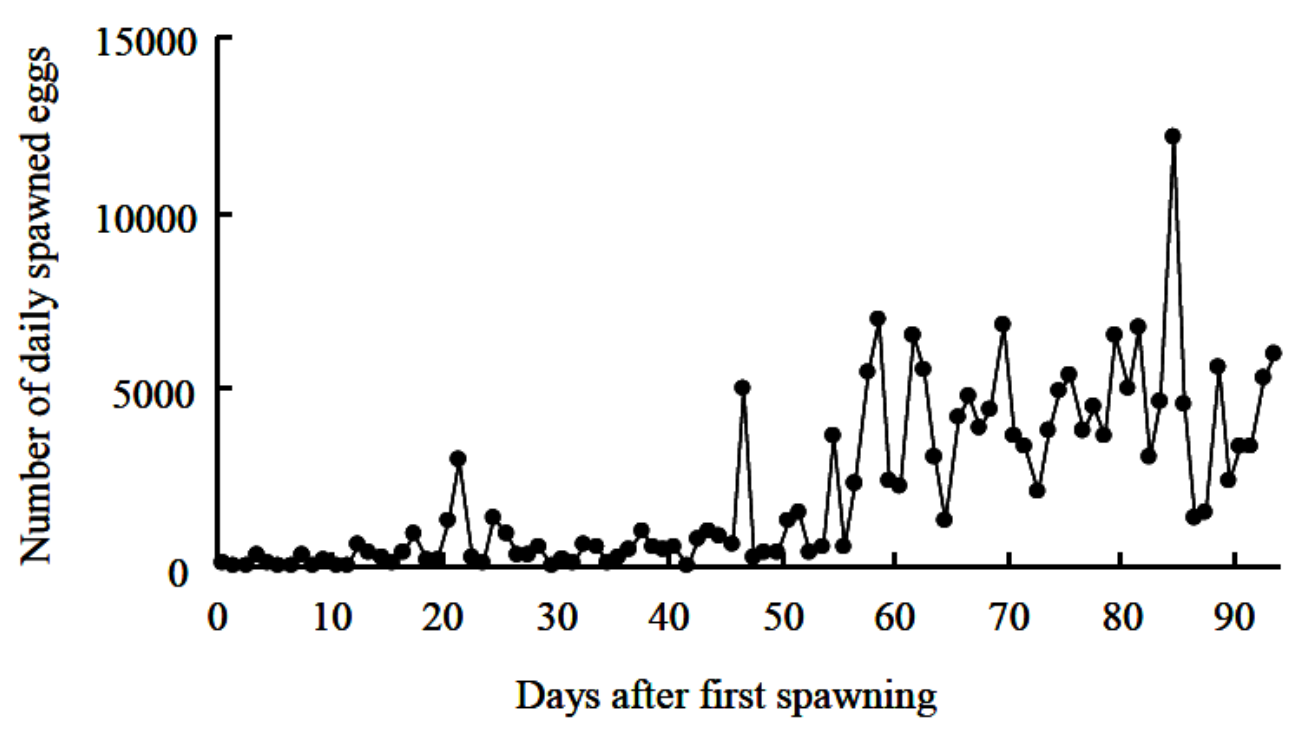

Fig. 9 Nakaya et al. 